九州大学学術情報リポジトリ

Kyushu University Institutional Repository

Polystyrene-Cross-Linking Triphenylphosphine on Porous Monolith: Enhanced Catalytic Activity for Aryl Chloride Cross-Coupling in Bipha-sic Flow

Matsumoto, Hikaru

Department of Chemical Engineering, Kyushu University

Hoshino, $\mathrm{Yu}$

Department of Chemical Systems and Engineering, Kyushu University

Iwai, Tomohiro

Department of Chemistry, Hokkaido University

Sawamura, Masaya

Department of Chemistry, Hokkaido University

他

ht tp://hdl. hand le. net/2324/4479611

出版情報 : Industrial \& Engineering Chemistry Research. 59 (34)，pp.15179-15187, 2020-07-31. American Chemical Society

バージョン :

権利関係 : 


\title{
Polystyrene-Cross-Linking Triphenylphosphine on Porous Monolith: Enhanced Catalytic Activity for Aryl Chloride Cross-Coupling in Bipha- sic Flow
}

\author{
Hikaru Matsumoto, ${ }^{\dagger}$ Yu Hoshino, ${ }^{\dagger}$ Tomohiro Iwai, ${ }^{\ddagger}$ Masaya Sawamura, ${ }^{*, \neq, \S}$ and Yoshiko Miura*,†
}

†Department of Chemical Engineering, Kyushu University, 744 Motooka, Nishi-ku, Fukuoka 819-0395, Japan

‡Department of Chemistry, Hokkaido University, Sapporo 060-0810, Japan

§Institute for Chemical Reaction Design and Discovery (WPI-ICReDD), Hokkaido University, Kita 21 Nishi 10, Kita-ku, Sapporo, 001-0021, Japan

\begin{abstract}
Immobilized transition metals for continuous-flow catalyses are greatly in demand to achieve automation, scaleup, facile separation, regeneration, and energy-saving production with high level of sustainability and efficiency. Here, we report a tertiary phosphine immobilized on a macroporous monolith (M-PS-TPP) for challenging Pd-catalyzed cross-coupling reaction of aryl chloride in continuous-flow system. The monolithic and macroporous structure of M-PS-TPP was fabricated by bulk polymerization in the presence of high internal phase emulsion (HIPE) template. Owing to the large pore size and high porosity, the M-PS-TPP showed high permeability against continuous flow of mobile phase. Continuous-flow SuzukiMiyaura cross-coupling reaction was realized by permeation of organic/aqueous media containing inorganic salt through Pdloaded monolith (M-PS-TPP-Pd) column without serious clogging. Controlling coordination chemistry and hydrodynamics of M-PS-TPP-Pd boosted highly active phosphine-metal complex forming and fast mass transfer of reactants. Indeed, the M-PSTPP-Pd column showed surprisingly higher yields ( 93\%) and turnover numbers (2704) in continuous-flow conditions than those in batch conditions $(\sim 6 \%)$.
\end{abstract}

\section{INTRODUCTION}

Continuous-flow syntheses of high-value organic molecules have attracted much attention for the production of pharmaceuticals, agrochemicals, fragrance, dyes, and organic electroluminescence devices. ${ }^{1}$ The benefits of continuous-flow operation relate to the simplification and implementation of procedures, which facilitate automation, ondemand production, scale-up, and also make the reaction system safer compared with batch systems. ${ }^{2}$ Transitionmetal-catalyzed reactions are of great interest because of their high catalytic activities and selectivities, and various metals, ligands, and substrates have been studied in this respect. An immobilized metal catalyst in a continuous-flow reactor can potentially better facilitate separation and reuse processes than homogeneous catalysts. ${ }^{3}$ Continuousflow syntheses using an immobilized catalyst are important in fine chemical production as they provide a high level of sustainability and efficiency.

C-C or C-heteroatom cross-coupling reactions via transition-metal catalyses are strong tools for production of pharmaceuticals or agricultural drugs. Recently, the use of continuous-flow systems in cross-coupling reactions has attracted much attentions in both academia and industry. ${ }^{4}$ Although aryl iodides, aryl bromides, or aryl triflates have been used as cross-coupling partners with aryl boronic acids, use of more inexpensive aryl chlorides is desired, where activation of $\mathrm{C}-\mathrm{Cl}$ is very challenging. ${ }^{5}$ Many researchers have demonstrated that sophisticated design of ligands toward metals can promote catalytic performance under mild conditions. ${ }^{6}$ Among them, tertiary phosphines are important ligands for transition-metal catalysts and have been immobilized on support materials. In fact, the resulting immobilized catalyst systems exhibit high activity, durability, and easy separation in various cross-coupling reactions containing aryl chlorides. ${ }^{7}$ However, while some reports continuous-flow system for cross-coupling reactions of aryl chlorides using immobilized catalysts, severe reaction conditions such as elevated temperature $\left(>80^{\circ} \mathrm{C}\right)$ or microwave assistance are needed. ${ }^{8}$

To obtain sustainable continuous-flow cross-coupling reaction, careful reactor design is necessary to avoid serious clogging of channel by insoluble salt in organic solvent during process. ${ }^{9}$ Moreover, use of soluble organic base have resulted in very few successes and sometimes needs relatively high temperature $\left(>100^{\circ} \mathrm{C}\right)$ or microwave assistance. ${ }^{10}$ One solution for this dilemma was proposed by Buchwald and co-workers, where organic/aqueous biphasic solvent was used to dissolve all the reactants in continuous-flow $\mathrm{C}-\mathrm{N}$ cross-coupling reactions employing homogeneous $\mathrm{Pd}$ catalyst. ${ }^{11}$ In biphasic reaction conditions, well mixing of reactants is necessary to maintain a large reaction interface during continuous-flow process, which leads to high productivity. To translate this biphasic condi-

tion into immobilized catalyst system, controlling hydrody- 


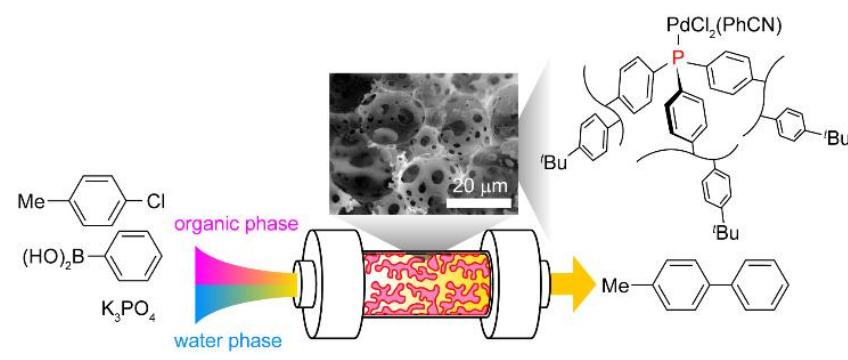

Figure 1. Macroporous polystyrene-triphenylphosphine monolith (M-PS-TPP) to Pd-catalyzed cross-coupling reaction containing aryl chloride in continuous-flow system.

namics of reactant solutions would be important for fast mass transfer and maximized performance of immobilized catalyst in continuous-flow reactor. ${ }^{12}$

The combination of organic chemistry and material sciences has led to immobilized catalyst systems developed for challenging chemical transformations on the laboratory or industrial scale. Porous materials show great potential in catalytic systems because of their controllable pore size and large surface area, which can boost the performance of the immobilized catalyst. ${ }^{13}$ Increasing demand for practical support materials has motivated the development of porous synthetic polymers because of their ease of preparation, flexible chemical functionalization, high stability, and insolubility. ${ }^{14}$ For example, Zhan and co-workers reported a microporous organic polymer supporting a triphenylphosphine (TPP) ligand for the cobalt-catalyzed hydrosilylation reaction in a continuous-flow system. ${ }^{15}$ In continuous-flow reactors using immobilized catalysts, packedbed columns have been widely used. However, continuousflow permeation through this column is accompanied by high pressure loss and broad residence time distribution (RTD), which is detrimental to the sustainability and efficiency of the process. ${ }^{16}$ On the other hand, macroporous monoliths consist of a single column with flow-through macropores, and show low pressure loss and narrow RTD in continuous-flow applications because of their controlled and large pore size and high porosity. ${ }^{17,18}$ We also believe that hydrodynamic properties of monolith allow fast mixing of biphasic reaction mixture to overcome mass transfer limitation in continuous-flow cross-coupling reactions, which show better catalytic efficiencies than those under batch conditions.

Scheme 1. (a) Synthesis of M-PS-TPP, (b) Preparation of M-PS-TPP Column, and (c) Continuous-Flow Setup for CrossCoupling Reaction between 4-Chlorotoluene and Phenylboronic Acid.

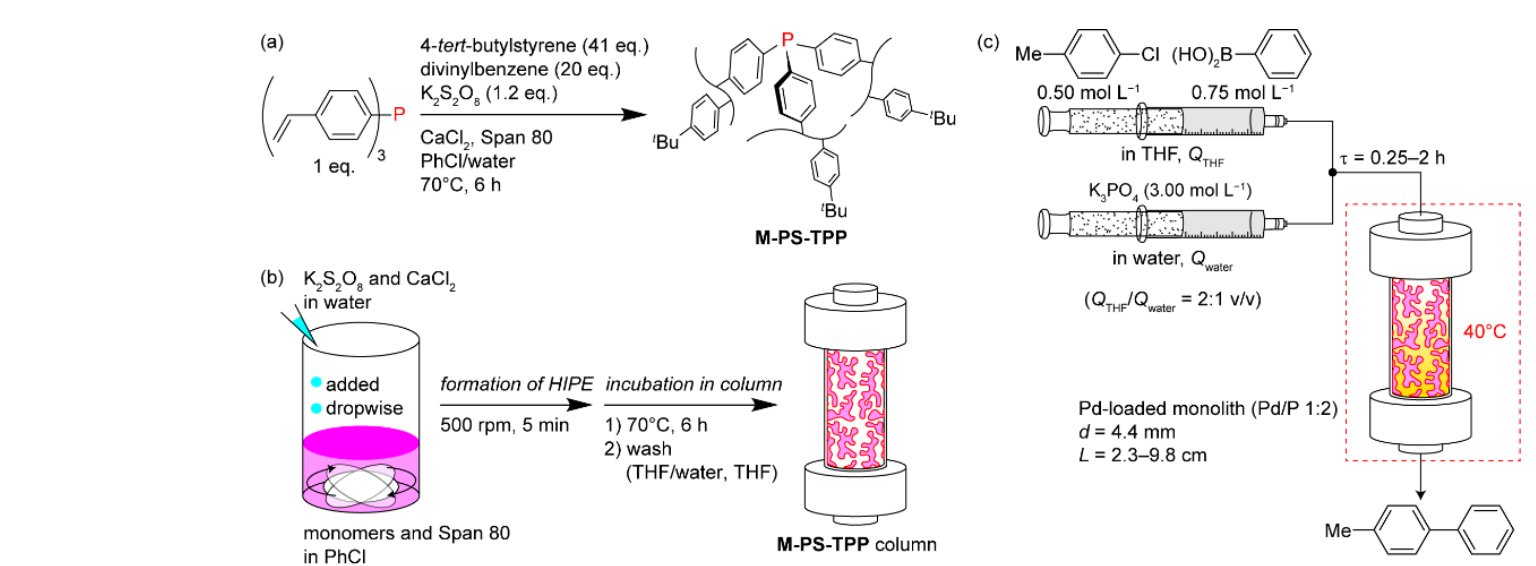

(b) $\mathrm{K}_{2} \mathrm{~S}_{2} \mathrm{O}_{8}$ and $\mathrm{CaCl}_{2}$
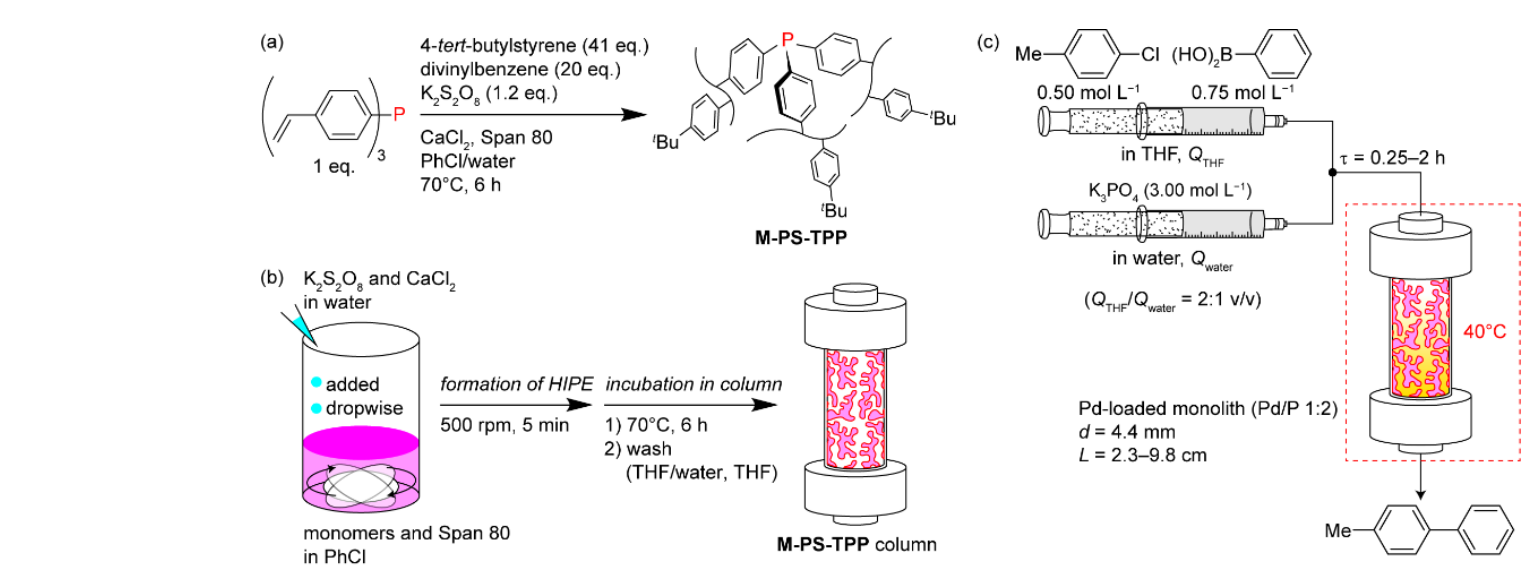

Here, we report a combination of sophisticated design of ligand and porous materials for challenging chemical transformation in continuous-flow manner. A three-fold crosslinking TPP on polystyrene monolith (M-PS-TPP) was fabricated by radical polymerization in the presence of a waterin-oil-type high internal phase emulsion (HIPE). ${ }^{19.20}$ This monolithic material had a characteristic window and void structure with a large pore size and high porosity. ${ }^{31} \mathrm{P}$ $\mathrm{CP} / \mathrm{MAS}$ NMR analyses were indicative of unique coordination behavior of the M-PS-TPP for mono-P-ligation toward Pd. To realize a continuous-flow system, a M-PS-TPP column was fabricated polymerizing the HIPE in a stainlesssteel column. The resulting M-PS-TPP column showed excellent hydrodynamic properties such as high permeability and narrow RTD of feed. These features were attractive to continuous-flow cross-coupling reactions. In fact, continuous permeation of 4-chlorotoluene and phenylboronic acid in $\mathrm{THF}$, and $\mathrm{K}_{3} \mathrm{PO}_{4}$ in water at $40{ }^{\circ} \mathrm{C}$ through a Pd-loaded $\mathbf{M}$ PS-TPP (M-PS-TPP-Pd) column allowed the SuzukiMiyaura cross-coupling reaction to proceed without clogging in the continuous-flow reactor (Figure 1). Controlling the hydrodynamic parameters in M-PS-TPP-Pd column provided the enhanced mass transfer, resulting in high productivity and durability during continuous-flow process. A proof-of-concept study demonstrated the advantages of the continuous-flow system using the monolith column supporting three-fold cross-linking TPP over the batch system and conventional TPP-grafted monolith column.

\section{RESULTS AND DISCUSSION}

Synthesis and Characterization of M-PS-TPP. To a solution of tris(4-vinylphenyl)phosphane (0.016 mmol, 1 eq.), 4-tert-butylstyrene (0.66 mmol, 41 eq.), divinylbenzene (0.32 mmol, 20 eq.), and surfactant Span $80(0.061 \mathrm{~mL})$ in chlorobenzene $(0.19 \mathrm{~mL})$ was added dropwise aqueous phase containing $\mathrm{CaCl}_{2}(0.33 \mathrm{mmol}), \mathrm{K}_{2} \mathrm{~S}_{2} \mathrm{O}_{8}(0.019 \mathrm{mmol}$, 1.2 eq.), and water ( $3.3 \mathrm{~mL}$ ) under vigorous stirring. ${ }^{21,22}$ The ratio of organic phase to aqueous phase was 10:90 v/v. After addition of the aqueous phase, stirring was further continued for 5 min to give the HIPE. For characterization, $\mathbf{M -}$ PS-TPP was prepared in a glass vial $(21.0 \mathrm{~mm}$ inner diameter) in which the HIPE was incubated at $70{ }^{\circ} \mathrm{C}$ for $6 \mathrm{~h}$ after removing the stirring bar (Scheme $1 \mathrm{a}$ ). 
After carefully crushing the vial, the resulting polymer was washed successively by immersion in THF/water $(2: 1 \mathrm{v} / \mathrm{v})$ and THF for $>1$ day each. The high cross-linking density in the polymer phase resulted in the THF-swollen M-PS-TPP being self-standing (Figure 2a), which was a necessary characteristic of a monolith column. The diameter $(d)$ of swollen M-PS-TPP differed in THF $(d=22.0 \mathrm{~mm})$ and THF/water $(d$ $=21.4 \mathrm{~mm}$ ). These $d$ values were larger than the inner diameter of the glass vial $(21.0 \mathrm{~mm})$ used as the mold. In a column reactor, the moderate swelling of M-PS-TPP would compensate for gaps between the column wall and monolith surface which could potentially allow a bypass flow of reactant. ${ }^{23}$ The swollen M-PS-TPP was dried under vacuum at room temperature overnight, to give a white solid polymer (92 wt.\% dry yield). ${ }^{24}$ The amount of the TPP moiety incorporated ([P]) was $0.11 \mathrm{mmol} \mathrm{g}^{-1}$ based on the feed ratio of the monomers. (a)

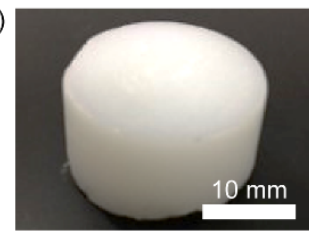

(b)

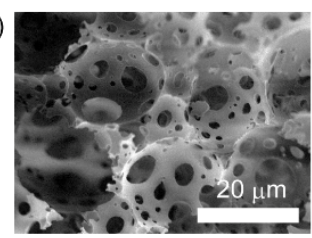

(d)

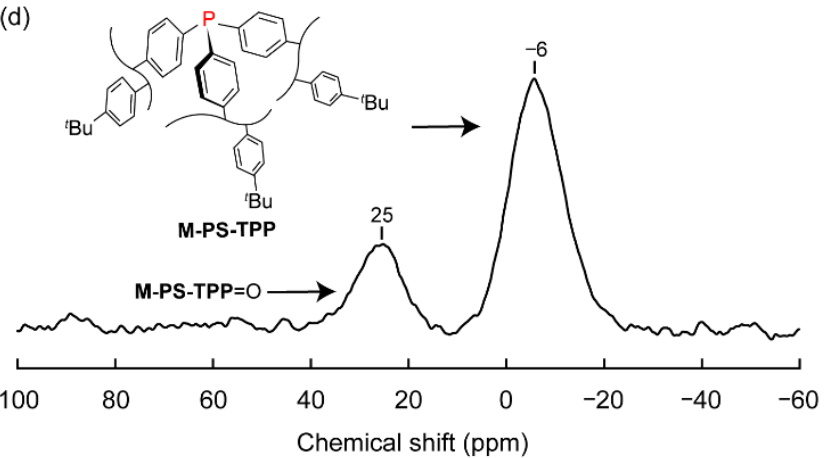

Pore size diameter $(\mathrm{m})$

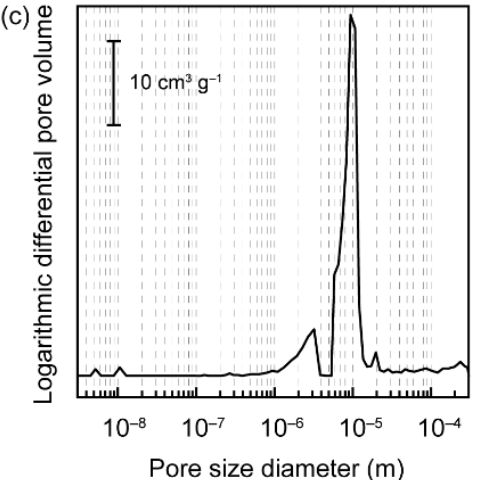

Figure 2. (a) THF-swollen photograph, (b) FE-SEM image, (c) Pore size distribution, and (d) 31P CP/MAS NMR spectra of MPS-TPP.

The dried M-PS-TPP was observed using FE-SEM, which revealed the characteristic window and void structure (Figure 2b). The observed voids were negative images of the aqueous phase in the HIPE, which were inter-connected with neighbors during polymerization. ${ }^{21}$ Mercury intrusion porosimetry analysis indicated that M-PS-TPP had a bimodal pore size distribution curve with $1^{\text {st }}$ and $2^{\text {nd }}$-mode pore sizes of 10690 and $3600 \mathrm{~nm}$, respectively (Table S2 and Figure 2c). The porosity of M-PS-TPP was $81 \%$, which was smaller than the volume ratio of the aqueous phase $(90$ vol\%) in the HIPE template. Nevertheless, the large flowthrough pores and high porosity of M-PS-TPP were expected to provide continuous-flow catalysis in a column reactor. The ${ }^{31} \mathrm{P} \mathrm{CP} / \mathrm{MAS}$ NMR spectra (Figure $2 \mathrm{~d}$ ) of the $\mathbf{M}$ PS-TPP confirmed the incorporation of coordinatively active TPP (-6 ppm) accompanied by some contents of TPP oxide (25 ppm) due to partial oxidation of the P atom during synthesis of monolith.

Coordination Behavior of M-PS-TPP. The coordination ability of M-PS-TPP toward Pd was confirmed by ICPAES and ${ }^{31} \mathrm{P} \mathrm{CP} / \mathrm{MAS}$ NMR analyses after treatment with $\left[\mathrm{PdCl}_{2}(\mathrm{PhCN})_{2}\right]$ in THF (Pd/P 1:2). ${ }^{25}$ ICP-AES analysis indicated that the Pd source in THF was completely loaded on M-PS-TPP to give a Pd loading ([Pd]) of $0.05 \mathrm{mmol} \mathrm{g}^{-1} .{ }^{31} \mathrm{P}$ CP/MAS NMR results were consistent with the formation of the TPP-Pd complex in the monolith, which indicated that M-PS-TPP favored a mono-P-ligated PdII complex (29 ppm) (Figure 3a). In contrast, a single-point grafting TPP on monolith (M-PS-grafted-TPP) ${ }^{22}$ preferentially showed bis-P-ligation (24 ppm) toward Pd over mono-P-ligation (32 ppm) (Figure 3b). The selective mono-P-ligation of M-PS-TPP was attributed to three-fold cross-linking around TPP, which was site-isolated in polymer network and thus favored mono-P-ligation towards $\mathrm{Pd}^{\mathrm{II}}$. This mono-ligated TPP-Pd complex reportedly leads to excellent activity in challenging transition-metal-catalyzed reactions. . $^{\text {a,b }}$

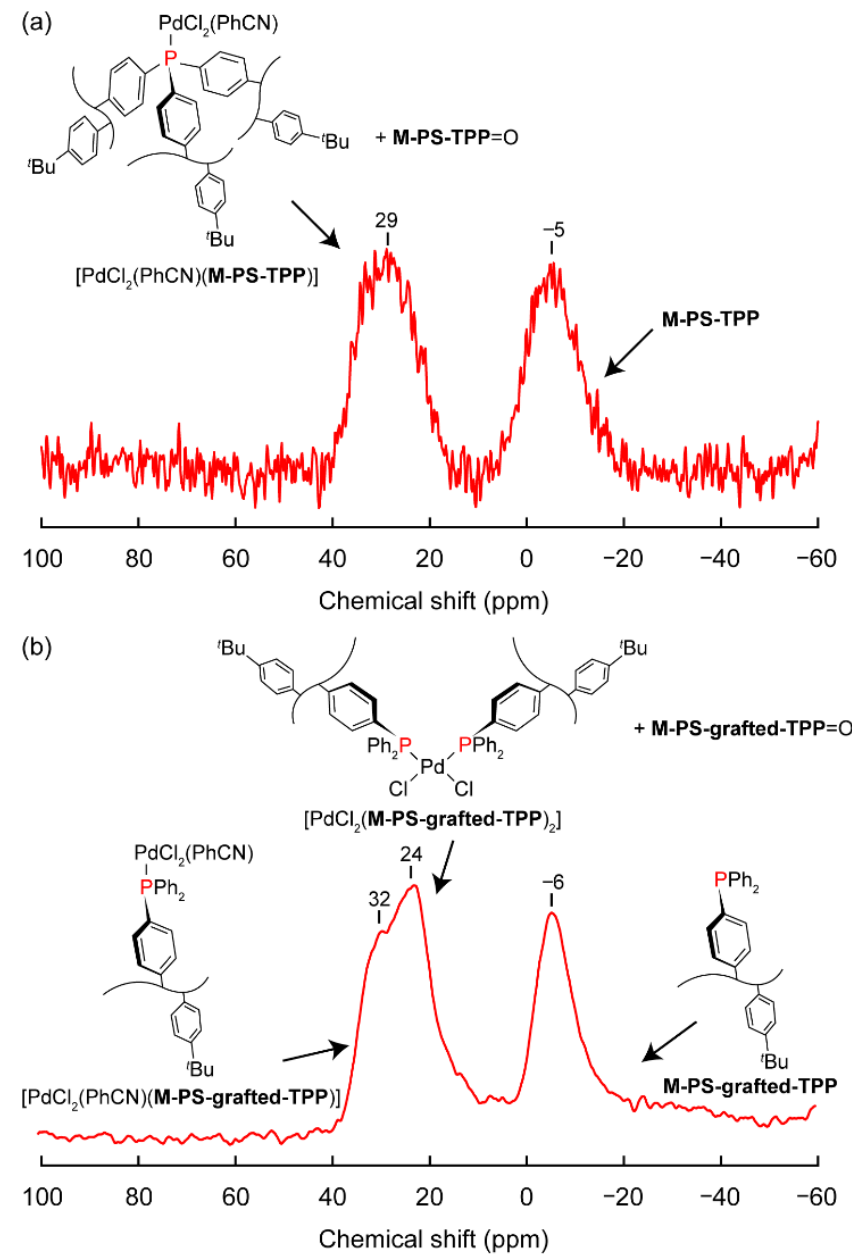

Figure 3. ${ }^{31} \mathrm{P} \mathrm{CP} / \mathrm{MAS}$ NMR spectra obtained (a) from M-PSTPP and [ $\mathrm{PdCl}_{2}\left(\mathrm{PhCN}_{2}\right]$ (Pd/P 1:2), and (b) from M-PSgrafted-TPP and $\left[\mathrm{PdCl}_{2}(\mathrm{PhCN})_{2}\right](\mathrm{Pd} / \mathrm{P} 1: 2)$.

Preparation and Characterization of Monolith Column for Continuous-Flow Application. Having confirmed the formation of flow-through macropores and selective mono-P-ligation in M-PS-TPP, M-PS-TPP was applied to 
continuous-flow application in a column reactor. ${ }^{26}$ Stainless-steel tube ( $4.4 \mathrm{~mm}$ inner diameter) was filled with monomer-containing HIPE using a syringe, and the column ends were then sealed with septa. Three different length of the stainless-steel tube $(2.5,5.0$, or $10.0 \mathrm{~cm}$ length) was used to prepare M-PS-TPP columns with different lengths $(L)$. After incubation at $70{ }^{\circ} \mathrm{C}$ for $6 \mathrm{~h}$ and subsequent permeation of THF/water $(2: 1 \mathrm{v} / \mathrm{v})$ and THF for washing, a M-PS-TPP column was fabricated (Scheme 1b). In the continuous-flow reactor, the pressure loss $(\Delta P)$ through the M-PS-TPP column was monitored at residence times $(\tau)$ of $0.25-2.00 \mathrm{~h}$ by varying the linear velocity $(u)$. During permeation of THF/water $(2: 1 \mathrm{v} / \mathrm{v})$ or THF, $\Delta P$ reached steady state and was stable for more than $72 \mathrm{~h}$. The steadystate value of $\Delta P$ increased proportionally with increasing $u$ of the mobile phase, which showed the high mechanical stability of M-PS-TPP against continuous permeation through the column reactor. The Darcy's permeabilities $\left(k_{\mathrm{D}}\right)$ of monolith columns with $L$ of $4.0 \mathrm{~cm}$ were $3.3 \times 10^{-13}$ and $3.8 \times 10^{-14} \mathrm{~m}^{2}$ for THF/water $(2: 1 \mathrm{v} / \mathrm{v})$ and THF, respectively. The M-PS-TPP column with shorter or longer $L$ values $\left(2.3\right.$ or $9.5 \mathrm{~cm}$ ) had almost the same $k_{\mathrm{D}}$ (Figure $4 \mathrm{a}$ ). When using M-PS-grafted-TPP column, the $k_{\mathrm{D}}$ were similar to that of M-PS-TPP column. These observation revealed that the absence of effect of ligand or column length on permeability of monolith column fabricated via HIPE template. Although pressure losses were rather greatly affected by monolith swelling in the mobile phase, the observed $k_{\mathrm{D}}$ values were comparable to those of a polystyrene monolith previously reported. ${ }^{27}$ The continuous permeation of the mobile phase was achieved with low pressure loss because of the large pore size and high porosity of M-PS-TPP, which gave sustainable continuous-flow operation.

In order to understand and control the variables governing the hydrodynamics, M-PS-TPP column was characterized by means of RTD studies using pulse tracer. An inert tracer dye, methyl red, was injected into the stream of THF through the M-PS-TPP column and its distribution was continuously monitored using in-line UV-vis spectroscopy at the outlet over time. ${ }^{28}$ Calculating the dimensionless time $(\theta)$ and dimensionless RTD function $(E(\theta))$, the flow behavior of methyl red was analyzed (Figure $4 \mathrm{~b}$ ). It was noteworthy that the narrow and high $E(\theta)$ curves were observed for M-PS-TPP column. Moreover, the flow patterns were independent on the $\tau$ of $0.25-2.00 \mathrm{~h}$ and repeated at least three times in each condition. These evaluations demonstrated that the flow-through porous structure of M-PS-TPP was a very suitable for support material of immobilized catalyst in continuous-flow reactor, where the flow presents little axial dispersion and thus is closer to plug flow than in the case of packed-bed material. ${ }^{18}$ Additionally, we estimated total porosity of M-PS-TPP column in continuous-flow reactor from the elution volume of pulse tracer, ${ }^{28}$ and realized that M-PSTPP had significantly higher porosity (91-98\%) than those obtained from mercury intrusion porosimetry (81\%). This was due to M-PS-TPP swelling in organic solvent, ${ }^{29}$ which would provide the full molecular diffusion of reactants toward catalytic center and maximize the performance of continuous-flow reactor. ${ }^{30}$

Effect of Residence Time and Column Length on Productivity. The M-PS-TPP-Pd column was fabricated by the reaction of the M-PS-TPP column with $\left[\mathrm{PdCl}_{2}(\mathrm{PhCN})_{2}\right]$ in THF under continuous-flow conditions. ${ }^{31}$ After washing by permeating with THF, the concentration of $\mathrm{Pd}$ in the eluent from the column was below the ICP-AES detection limit ( $<10 \mathrm{ppb}$ ), and the loading amount of Pd in M-PS-TPP-Pd was $0.05 \mathrm{mmol} \mathrm{g}^{-1}$ (Pd/P 1:2). The continuous-flow SuzukiMiyaura cross-coupling reaction between 4-chlorotoluene $\left(0.50 \mathrm{~mol} \mathrm{~L}^{-1}, 1\right.$ eq.) and phenylboronic acid $(0.75 \mathrm{~mol} \mathrm{~L}-1$, 1.5 eq.) was used to evaluate the productivity of the M-PSTPP-Pd column. THF solution of the aryl substrates and aqueous solution of $\mathrm{K}_{3} \mathrm{PO}_{4}$ (3.00 mol L-1, 3 eq.) was pumped and mixed via a T-shaped mixer. The $\tau$ of the substrate solution was set in the range of $0.25-2.00 \mathrm{~h}$ by changing the $Q$ while maintaining the ratio of the THF phase
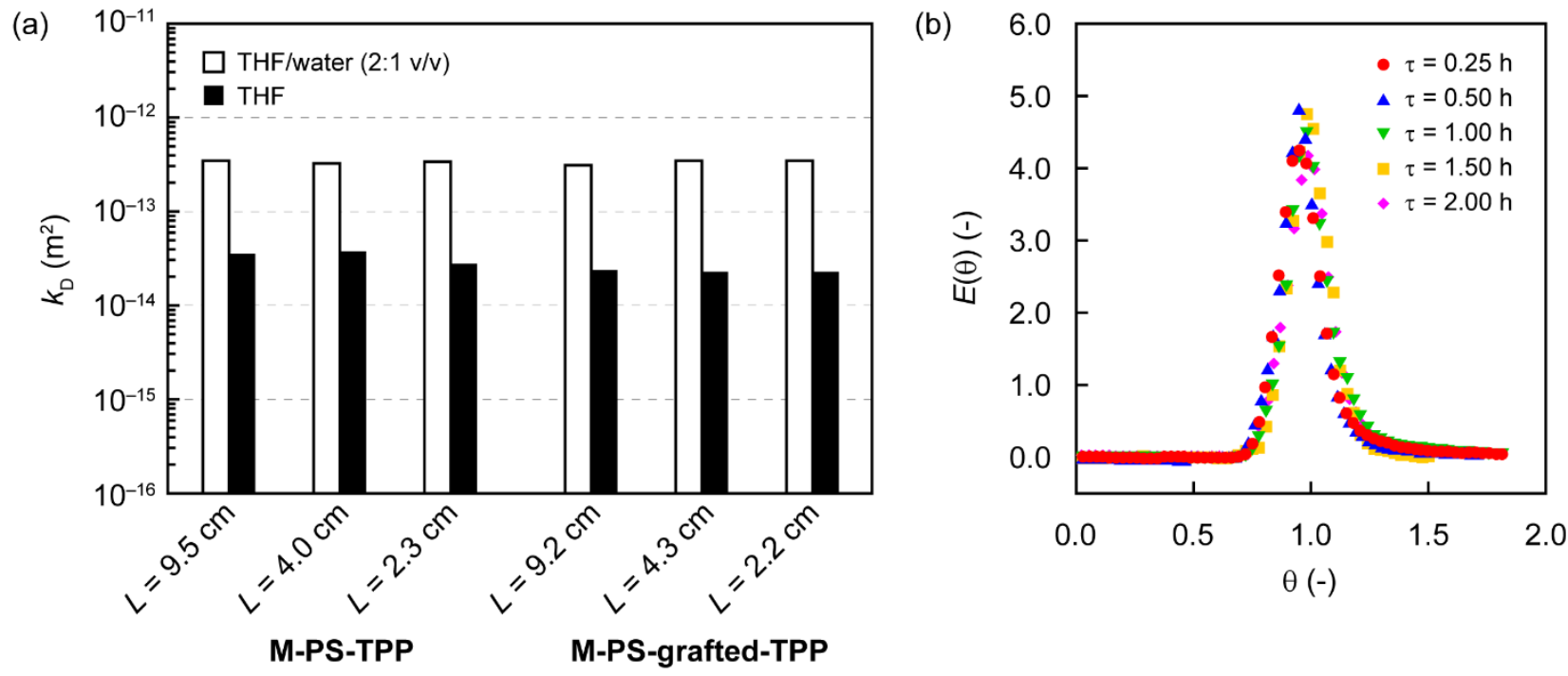

Figure 4. (a) Permeation coefficients $\left(k_{\mathrm{D}}\right)$ of monolith column with different mobile phase and column length $(L)$. (b) Representative dimensionless residence time distribution function $(E(\theta))$ v.s. dimensionless time $(\theta)$ diagram for a pulse injection of methyl red in ethanol $\left(1 \mathrm{~g} \mathrm{~L}^{-1}, 10 \mu \mathrm{L}\right)$ into a THF stream through M-PS-TPP column $(L=4.5 \mathrm{~cm})$. 
$\left(Q_{\mathrm{THF}}\right)$ to water phase $\left(Q_{\text {water }}\right)$ at $2: 1 \mathrm{v} / \mathrm{v}\left(Q=Q_{\mathrm{THF}}+Q_{\text {water }}\right)$ (Scheme 1c). During elution from the column, macroscopic phase separation rapidly occurred, and the THF phase was analyzed using HPLC to confirm the production of 4methylbiphenyl. Under the present conditions, byproducts such as biphenyl which might originate from homo-coupling of phenylboronic acids were not found. During permeation of the substrate solution at a time on stream of $4-10 \mathrm{~h}$ (early region), the yield of 4-methylbiphenyl was determined for each $\tau$. The yield of 4-methylbiphenyl depended on the $\tau$ of the substrate solution (filled circle, filled triangle, and filled rectangle, Figure 5). The M-PS-TPP-Pd column with a short $L(2.3 \mathrm{~cm})$ gave a very poor yield $(8 \%$, filled rectangle) at a $\tau$ of $2.00 \mathrm{~h}$. Increasing the $L$ of the M-PS-TPPPd column drastically increased the yield within the same range of $\tau$ values. At a $\tau$ of $2.00 \mathrm{~h}$, the M-PS-TPP-Pd column with longer $L$ values ( 4.0 and $9.5 \mathrm{~cm}$ ) achieved excellent yields of 86 and $88 \%$, respectively.
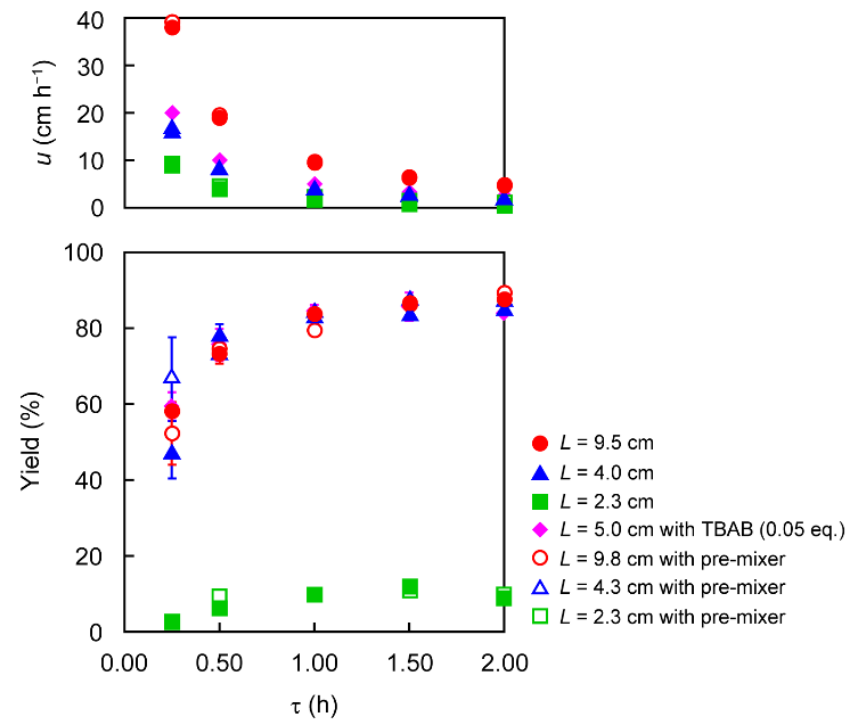

Figure 5. Effects of column length $(L)$ of M-PS-TPP-Pd column and residence time $(\tau)$ on yield of 4-methylbiphenyl in continuous-flow Suzuki-Miyaura cross-coupling reaction using biphasic solvent. Conditions: 4 -chlorotoluene $\left(0.50 \mathrm{~mol} \mathrm{~L}^{-1}, 1\right.$ eq.) and phenylboronic acid (0.75 mol L-1, 1.5 eq.) in THF, $\mathrm{K}_{3} \mathrm{PO}_{4}$ (3.00 mol L-1, 3 eq.) in water, M-PS-TPP-Pd column $(\mathrm{Pd} / \mathrm{P} 1: 2)$, THF phase/water phase $2: 1 \mathrm{v} / \mathrm{v}, 40^{\circ} \mathrm{C}$.

Buchwald and co-workers reported that increasing the $u$ improved the yield of the $\mathrm{C}-\mathrm{N}$ cross-coupling reaction in toluene/water media using homogeneous Pd. ${ }^{11}$ In our system, a higher $u$ was realized using a longer $L$ at the same range of $\tau$ (Figure 5). We assumed that this positive effect was attributed to the fast mass transfer at the organic/aqueous interface enhanced by higher $u$. To verify the importance of interfacial mass transfer for the biphasic media, glass beads (1.0-1.4 mm diameter) were packed in a stainless-steel tube ( $4.4 \mathrm{~mm}$ inner diameter, $5.0 \mathrm{~cm}$ length) as a pre-mixer, which was installed upstream of the M-PSTPP-Pd column. However, the effect of pre-mixing on the yield was not obvious compared with the effect of the $L$ of the M-PS-TPP-Pd column (blank circle, blank triangle, and blank rectangle, Figure 5 ). In the presence of tetra- $n$-butylammonium bromide (TBAB, 0.05 eq.) as a phase transfer catalyst in the biphasic reaction mixture, the productivity of the M-PS-TPP-Pd column was also evaluated (filled rhombus, Figure 5), which gave almost the same trend as that without using TBAB.

Unlike the previous study using a homogeneous catalyst, ${ }^{11}$ the present results demonstrated that mass transfer at the liquid/liquid interface was not the rate-limiting step using the immobilized catalyst on the monolith reactor. Increasing the $u$ accelerated the liquid/liquid interfacial mass transfer and also external diffusion on the M-PS-TPP-Pd surface. ${ }^{32}$ This may have been the rate-limiting step in the continuous-flow system with a short $L(\sim 2.3 \mathrm{~cm})$. With longer $L$ values ( $4.0 \mathrm{~cm}$ or more), the yield profiles were almost the same, suggesting sufficiently fast diffusion at organic/aqueous interface, featuring efficient mixing through macropore of M-PS-TPP-Pd column. In addition to RTD behavior close to plug-flow (Figure $4 \mathrm{~b}$ ), the accelerated external diffusion of reactants also boosted productivity of monolith column.

Long-Term Durability of M-PS-TPP-Pd Column. At a $\tau$ of $2.00 \mathrm{~h}$, the long-term durability of the M-PS-TPP-Pd column was evaluated using the Suzuki-Miyaura cross-coupling reaction under continuous-flow conditions (time on stream of 58 h) (Figure 6). From ICP-AES analyses, Pd leaching from the column was not observed $(<10 \mathrm{ppb})$ in any eluent (THF and water phase). This suggested the effective entrapment of Pd by the cross-linked polymer network in the M-PS-TPP-Pd column during long-term use. ${ }^{30}$ The gradual decrease in the turnover numbers (TONs) of the monolith columns was observed along with permeation of the substrate solutions. TEM observations of original and spent Pd-loaded monoliths indicated the formation of clusters likely generated from Pd aggregation, which should be less active or inactive. ${ }^{33}$ The M-PS-TPP-Pd column reached a very high TON of 2704 at a time on stream of $58 \mathrm{~h}$ in the continuous-flow cross-coupling reaction of aryl chloride.

Effect of TPP Moiety on Productivity. To confirm the importance of the three-fold cross-linking around TPP in MPS-TPP-Pd on productivity, M-PS-grafted-TPP, where analogous TPP was covalently linked to a polystyrene chain via single-point grafting, was also used in the continuousflow reaction at a $\tau$ of $2.00 \mathrm{~h}$ (Figure 6). The productivity of the M-PS-grafted-TPP-Pd column with a short $L(2.2 \mathrm{~cm})$ was poor, giving a TON of 90 at a bed volume of 17 (violet rhombus, Figure 6). As with the M-PS-TPP-Pd column system (Figure 5), increasing the $L(4.3 \mathrm{~cm})$ of the M-PSgrafted-TPP-Pd column significantly improved the yield and TON (gray square, Figure 6). However, further increasing the $L(9.2 \mathrm{~cm})$ did not give any meaningful enhancement (black triangle, Figure 6). The absence of external diffusion limitation in the monolith column was apparent at $L$ values above $4.3 \mathrm{~cm}$ for the M-PS-graftedTPP-Pd column. All M-PS-grafted-TPP-Pd columns showed drastic decreases in productivities of 4methylbiphenyl with increasing time on stream, and no meaningful conversion was observed at bed volumes of 17 (5-10\% yields). Surprisingly, the highly durable catalysis of the M-PS-TPP-Pd column produced biaryl (63\% yield) at a bed volume of 17 . 

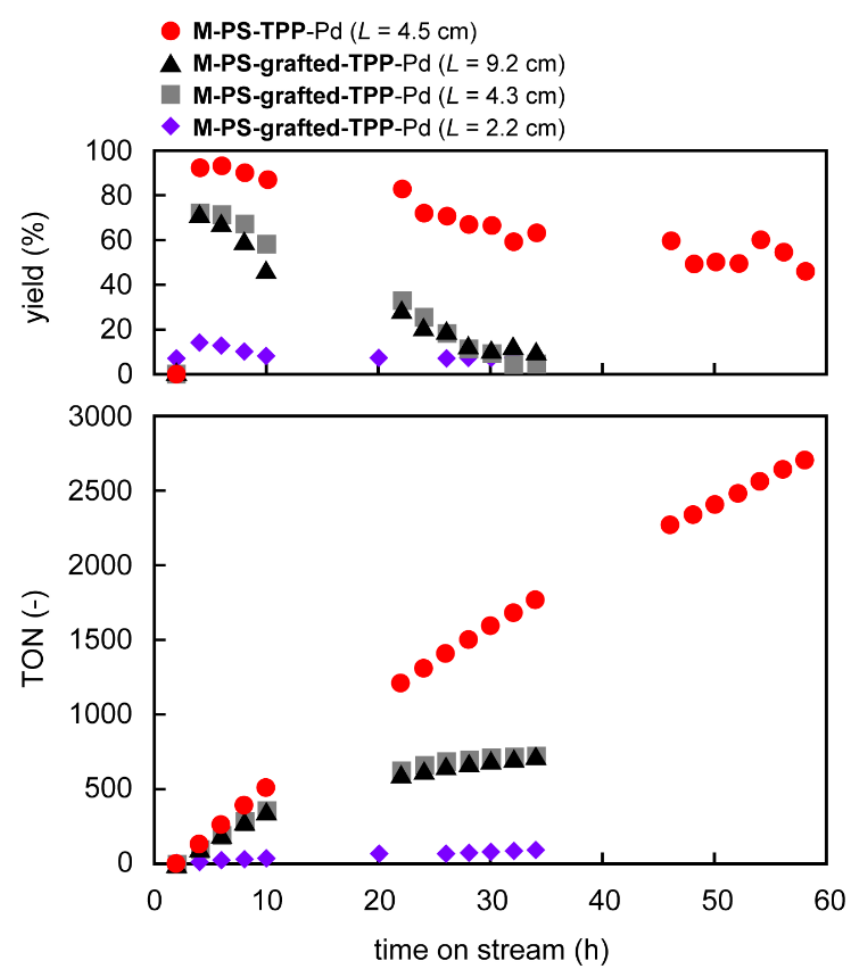

Figure 6. Long-term production of 4-methylbiphenyl using monolith reactors containing TPP-Pd complex. Conditions: 4chlorotoluene $\left(0.50 \mathrm{~mol} \mathrm{~L}^{-1}, 1\right.$ eq. $)$ and phenylboronic acid (0.75 mol L-1, 1.5 eq.) in $\mathrm{THF}, \mathrm{K}_{3} \mathrm{PO}_{4}$ (3.00 mol L-1, 3 eq.) in water, TPP-Pd on monolith column (Pd/P 1:2), THF phase/water phase $2: 1 \mathrm{v} / \mathrm{v}, \tau=2.00 \mathrm{~h}, 40^{\circ} \mathrm{C}$.

The efficient productivity of the M-PS-TPP-Pd column was apparent compared with those of the M-PS-graftedTPP-Pd columns. This suggested that TPP-Pd complex species in the monolith column greatly influenced the catalytic efficacy in the continuous-flow cross-coupling reaction. The three-fold cross-linking around TPP, which facilitated the formation of the mono-ligated TPP-Pd complex, was essential for participation in conversion of the unactivated aryl chloride under mild conditions $\left(40{ }^{\circ} \mathrm{C}\right) .^{7 \mathrm{a}, \mathrm{b}}$ The final TON (2704) of the M-PS-TPP-Pd column corresponded to a turnover frequency (TOF) of $47 \mathrm{~h}^{-1}$ and space time yield of 0.45 $\mathrm{kg} \mathrm{L}^{-1}$ day $^{-1}$. The potential of the M-PS-TPP column in Pdcatalyzed aryl chloride cross-coupling was comparable to that of a polymer-supported TPP bead column in similar cross-couplings of aryl bromides. ${ }^{34}$ Using the M-PS-TPP-Pd column, 4-chlorotoluene was continuously processed to produce the cross-coupling product, 4-methylbiphenyl, with a total yield of $0.728 \mathrm{~g}$ (time on stream of $58 \mathrm{~h}$ ). This yield could readily be scaled up using numbering up or size up strategies. ${ }^{1}$

Continuous-Flow Conditions v.s. Batch Conditions. The catalytic efficacy of M-PS-TPP-Pd was also evaluated in batch system ${ }^{35}$ and compared with that in continuous-flow system. Indeed, the TON and TOF of M-PS-TPP-Pd was higher under continuous-flow conditions than those under batch conditions (Table 1). Interestingly, increasing the stirring rate and/or employing TBAB enhanced the reaction efficacy of batch cross-coupling reaction using M-PS-TPP-Pd. This indicated severe diffusion limitation at organic/aqueous interface in the batch system. Most of studies on cross- coupling reactions showed the lower productivities of immobilized catalysts under continuous-flow conditions than those under batch conditions, ${ }^{36}$ which were probably due to low mixing and contact efficiency with catalyst. In our system, the merits of the macroporous architecture (Figure $2 \mathrm{~b}$ and c) of the M-PS-TPP-Pd column for mass transfer were highlighted, where molecular diffusion at the liquid/liquid interface was accelerated by the biphasic media co-flowing through the micron-sized pores. ${ }^{27}$ Moreover, the full accessibility of reactants toward catalyst was realized due to narrow RTD and swelling properties (Figure 4b) which also supported the high productivity of M-PS-TPP-Pd column. As far as we know, the present system is the first example of continuous-flow cross-coupling reaction of aryl chloride showing rather excellent efficacy and durability than that in batch system.

Table 1. Comparison of Catalytic Efficacies of M-PS-TPPPd for Aryl Chloride Cross-Coupling ${ }^{a}$

\begin{tabular}{llll}
\hline condition & yield (\%) & TON $(-)$ & TOF $\left(\mathrm{h}^{-1}\right)$ \\
\hline continuous flow $^{b}$ & $46-93$ & $2704^{c}$ & $47^{c}$ \\
batch $^{d}$ & 6 & 58 & 29
\end{tabular}

Conditions: 4-chlorotoluene $\left(0.50 \mathrm{~mol} \mathrm{~L}^{-1}, 1\right.$ eq. $)$ and phenylboronic acid $\left(0.75 \mathrm{~mol} \mathrm{~L}^{-1}, 1.5\right.$ eq.) in $\mathrm{THF}, \mathrm{K}_{3} \mathrm{PO}_{4}$ (3.00 mol L-1, 3 eq.) in water, THF phase/water phase 2:1 $\mathrm{v} / \mathrm{v}, 40^{\circ} \mathrm{C}$.

${ }^{b}$ M-PS-TPP-Pd column (Pd/P 1:2, $\left.L=4.5 \mathrm{~cm}\right), \tau=2.00 \mathrm{~h}$. ${ }^{c}$ Time on stream $=58 \mathrm{~h}$.

${ }^{d}$ M-PS-TPP-Pd (Pd/P 1:2, $\left.0.1 \mathrm{~mol} \% \mathrm{Pd}\right), 2.00 \mathrm{~h}$.

\section{CONCLUSIONS}

In summary, a macroporous polystyrene monolith containing three-fold cross-linking triphenylphosphine, M-PSTPP, was synthesized and applied to challenging transitionmetal catalysis in continuous-flow manner, which featured highly active phosphine-metal complex and enhanced hydrodynamic properties. Through radical polymerization in the presence of a HIPE, the characteristic window and void structure in M-PS-TPP was fabricated. M-PS-TPP in column format was applied to continuous-flow application and showed excellent permeability and narrow RTD of the feed. The feasibility of the M-PS-TPP column for continuous-flow synthesis was demonstrated in the Pd-catalyzed SuzukiMiyaura cross-coupling reaction of aryl chloride. Using organic/aqueous media, clogging in the continuous-flow reactor by salt formation was avoided. Controlling hydrodynamic properties in the M-PS-TPP-Pd column enhanced mass transfer and resulted in highly active and durable catalyst system without Pd leaching. The productivity of the MPS-TPP-Pd column in the continuous-flow system was much higher than that in the batch system, with the former featuring efficient mixing of biphasic media and selective mono-P-ligation toward PdII. The M-PS-TPP system could be broadly extended to transition-metal catalysis in continuous-flow systems for efficient production of fine chemicals.

\section{EXPERIMENTAL SECTIONS}

Synthesis of M-PS-TPP for Characterization (Scheme 1a). A solution of tris(4-vinylphenyl)phosphane $(5.5 \mathrm{mg}$, 
$0.016 \mathrm{mmol}, 1$ eq.), 4-tert-butylstyrene $(106.0 \mathrm{mg}, 0.66$ mmol, 41 eq.), divinylbenzene ( $42.0 \mathrm{mg}, 0.32 \mathrm{mmol}, 20$ eq.), and Span $80(0.061 \mathrm{~mL})$ in chlorobenzene $(0.19 \mathrm{~mL})$ was placed in a glass vial (21.00 $\mathrm{mm}$ inner diameter) equipped with a magnetic stirring bar $(\sim 20 \mathrm{~mm})$. The organic phase was degassed by three freeze-pump-thaw cycles. Separately, $\mathrm{CaCl}_{2}$ (36.9 mg, $0.33 \mathrm{mmol}$ ) and $\mathrm{K}_{2} \mathrm{~S}_{2} \mathrm{O}_{8}$ (5.2 mg, $0.019 \mathrm{mmol}$, 1.2 eq.) was dissolved in water $(3.3 \mathrm{~mL})$. The aqueous phase was degassed by nitrogen bubbling for $>0.5 \mathrm{~h}$. Under vigorous stirring of organic phase (500 rpm), the initiator-containing aqueous phase was added dropwise using syringe. The ratio of organic phase to aqueous phase was 10:90 v/v. After addition of aqueous phase, stirring was further continued for 5 min to give HIPE. The HIPE was incubated in the vial at $70^{\circ} \mathrm{C}$ for various time $(6 \mathrm{~h})$ after removing stirring bar. Carefully crushing the vial, the resulting cylindrical polymer was washed successively by immersion in THF/water $(2: 1 \mathrm{v} / \mathrm{v})$ and THF for $>1$ day each. Using calipers, the $d$ and $L$ of swollen M-PS-TPP was measured to estimate a swelling volume. The yield of M-PS-TPP was determined after drying under vacuum at room temperature overnight, to give a white solid polymer (141.5 mg, $92 \mathrm{wt} \%$ dry yield). The [P] of M-PS-TPP was $0.11 \mathrm{mmol} \mathrm{g}^{-1}$ based on feed ratio of monomers.

Synthesis of M-PS-TPP Column for Flow Application (Scheme 1b). Stainless-steel tube (4.4 mm inner diameter) with different length $(2.5,5.0$, or $10.0 \mathrm{~cm})$ was filled with HIPE using syringe and sealed at the ends with septa. After incubation at $70^{\circ} \mathrm{C}$ for $6 \mathrm{~h}$, the seals were removed, and the $L$ of monolith column within stainless-steel column was measured using calipers. For flow application, the M-PSTPP column was provided with fittings and attached to a syringe pump. THF/water $(2: 1 \mathrm{v} / \mathrm{v})$ and THF were successively permeated through the column for wash $(2.5 \mathrm{~h}$ each, $\tau=0.50 \mathrm{~h})$. At various $u(\tau=0.25,0.50,1.00,1.50$, or $2.00 \mathrm{~h})$, the pressure losses through the column were monitored for more than $48 \mathrm{~h}$ to reach steady-state condition. The $k_{\mathrm{D}}$ of monolith columns for each mobile phase were estimated.

Flow Suzuki-Miyaura Cross-Coupling Reaction in Biphasic Solvent System (Scheme 1c). $\left[\mathrm{PdCl}_{2}\left(\mathrm{PhCN}_{2}\right]\right.$ $\left(0.005 \mathrm{~mol} \mathrm{~L}^{-1}\right)$ in THF was permeated through M-PS-TPP column $(\tau=2.00 \mathrm{~h})$. The molar ratio of Pd to P was 1:2, controlled by total elution volume of feed solution. After completion of the permeation, the column was washed by permeation of THF to afford M-PS-TPP-Pd $(2.5 \mathrm{~h}, \tau=0.50 \mathrm{~h}) .4$ Chlorotoluene $\left(0.50 \mathrm{~mol} \mathrm{~L}^{-1}, 1\right.$ eq.) and phenylboronic acid (0.75 mol L-1, 1.5 eq.) in THF, and $\mathrm{K}_{3} \mathrm{PO}_{4}$ (3.00 $\mathrm{mol} \mathrm{L}^{-1}, 3$ eq.) in water were separately prepared. TBAB $(0.025 \mathrm{~mol} \mathrm{~L}-1$, 0.05 eq.) was dissolved in the THF phase with aryl substrates if needed. These solutions were loaded into syringes and attached to syringe pumps. Two syringe pumps were used to deliver the feed substrate solutions at controlled $Q_{\mathrm{THF}}$ and $Q_{\text {water. }}$ The ratio of $Q_{\mathrm{THF}}$ to $Q_{\text {water }}$ was 2:1. The two substrate solutions were pumped and mixed via T-shaped mixer. The mixture was continuously permeated through the M-PS-TPP-Pd column. The $\tau$ was calculated based on the total flow rate of THF-phase and water-phase substrate solutions $\left(Q=Q_{\mathrm{THF}}+Q_{\text {water }}\right)$. The elution from the column was continuously collected, and the THF-phase was analyzed using HPLC. During permeation of the substrate solution at a time on stream of 4-10 h (early region), the yield of 4-methylbiphenyl was determined for each $\tau$. After run, THF/water $(2: 1 \mathrm{v} / \mathrm{v})$ and THF was successively permeated through the column for washing. The eluent from the column was diluted in aqueous solution of $\mathrm{HCl}\left(1 \mathrm{~mol} \mathrm{~L}^{-1}\right)$ and analyzed using ICP-AES.

\section{ASSOCIATED CONTENT}

Experimental details, porous properties, NMR spectra, permeabilities, and other data for this study are available in Supporting Information and free of charge via the Internet at http://pubs.acs.org.

\section{AUTHOR INFORMATION}

\section{Corresponding Authors}

Masaya Sawamura - Department of Chemistry, Hokkaido University, Sapporo 060-0810, Japan; Institute for Chemical Reaction Design and Discovery (WPI-ICReDD), Hokkaido University, Kita 21 Nishi 10, Kita-ku, Sapporo, 001-0021, Japan; Email: sawamura@sci.hokudai.ac.jp

Yoshiko Miura - Department of Chemical Engineering, Kyushu University, 744 Motooka, Nishi-ku, Fukuoka 819-0395, Japan; Email: miuray@chem-eng.kyushu-u.ac.jp

\section{Author}

Hikaru Matsumoto - Department of Chemical Engineering, Kyushu University, 744 Motooka, Nishi-ku, Fukuoka 819-0395, Japan

Yu Hoshino - Department of Chemical Engineering, Kyushu University, 744 Motooka, Nishi-ku, Fukuoka 819-0395, Japan

Tomohiro Iwai - Department of Chemistry, Hokkaido University, Sapporo 060-0810, Japan

Notes

The authors declare no competing financial interest.

\section{ACKNOWLEDGMENT}

This work was supported by a JSPS KAKENHI Grant Number JP15H05801, JP16H01036, JP18J20345, JP19H02766, JP20H04793, JP2OH04825, and JP20H05230.

\section{REFERENCES}

(1) a) Masuda, K.; Ichitsuka, T.; Koumura, N.; Sato, K.; Kobayashi, S. Flow fine synthesis with heterogeneous catalysts. Tetrahedron 2018, 74, 1705-1730; b) Kobayashi, S. Flow "Fine" Synthesis: High Yielding and Selective Organic Synthesis by Flow Methods. Chem. Asian J. 2016, 11 425-436.

(2) Tsubogo, T.; Ishiwata, T.; Kobayashi, S. Asymmetric carboncarbon bond formation under continuous-flow conditions with chiral heterogeneous catalysts. Angew. Chem. 2013, 125, 6722-6737; Angew. Chem. Int. Edit. 2013, 52, 6590-6604.

(3) Cantillo, D.; Kappe, C. O. Immobilized Transition Metals as Catalysts for Cross-Couplings in Continuous Flow-A Critical Assessment of the Reaction Mechanism and Metal Leaching. ChemCatChem 2014, 6, 3286-3305.

(4) Plutschack, M. B.; Pieber, B.; Gilmore, K.; Seeberger, P. H. The Hitchhiker's Guide to Flow Chemistry. Chem. Rev. 2017, 117, 11796-11893.

(5) a) Polshettiwar, V.; Len, C.; Fihri, A. Silica-supported palladium: Sustainable catalysts for cross-coupling reactions. Coordin. Chem. Rev. 2009, 253, 21-22; b) Pagliaro, M.; Pandarus, V.; Ciriminna, R.; Béland, F.; Demma Carà, P. Heterogeneous versus Homogeneous Palladium Catalysts for Cross-Coupling Reactions. ChemCatChem 2012, 4, 432-445. 
(6) Berrisford, D. J.; Bolm, C.; Sharpless, K. B. Ligand-Accelerated Catalysis. Angew. Chem. 1995, 107, 1159-1171; Angew. Chem. Int. Ed. 1995, 34, 1059-1070.

(7) a) Iwai, T.; Asano, K.; Harada, T.; Sawamura, M. PolystyreneCross-Linking Ortho-Substituted Triphenylphosphines: Synthesis, Coordination Properties, and Application to PdCatalyzed Cross-Coupling of Aryl Chlorides. Bull. Chem. Soc. Japan 2017, 90, 943-949; b) Iwai, T.; Harada, T.; Hara, K.; Sawamura, M. Threefold Cross-Linked PolystyreneTriphenylphosphane Hybrids: Mono-P-Ligating Behavior and Catalytic Applications for Aryl Chloride Cross-Coupling and $\mathrm{C}\left(\mathrm{sp}^{3}\right)-\mathrm{H}$ Borylation. Angew. Chem. 2013, 125, 1254812552; Angew. Chem. Int. Ed. 2013, 52, 12322-12326; c) Li, B.; Guan, Z.; Wang, W.; Yang, X.; Hu, J.; Tan, B.; Li, T. Highly dispersed Pd catalyst locked in knitting aryl network polymers for Suzuki-Miyaura coupling reactions of aryl chlorides in aqueous media. Adv. Mater. 2012, 24, 33903395; d) Leyva, A.; García, H.; Corma, A. A soluble polyethyleneglycol-anchored phosphine as a highly active, reusable ligand for Pd-catalyzed couplings of aryl chlorides: comparison with cross and non-cross-linked polystyrene and silica supports. Tetrahedron 2007, 63, 7097-7111; e) Parrish, C. A.; Buchwald, S. L. Use of Polymer-Supported Dialkylphosphinobiphenyl Ligands for Palladium-Catalyzed Amination and Suzuki-Reaktions. J. Org. Chem. 2001, 66, 3820-3827.

(8) a) He, P.; Haswell, S. J.; Fletcher, P. D. I.; Kelly, S. M.; Mansfield, A. Scaling up of continuous-flow, microwave-assisted, organic reactions by varying the size of Pd-functionalized catalytic monoliths. Beilstein J. Org. Chem. 2011, 7, 1150-1157; b) Egle, B.; de Muñoz, J. M.; Alonso, N.; De Borggraeve, W. M.; de la Hoz, A.; Díaz-Ortiz, A.; Alcázar, J. First Example of AlkylAryl Negishi Cross-Coupling in Flow: Mild, Efficient and Clean Introduction of Functionalized Alkyl Groups. J. Flow Chem. 2014, 4, 22-25.

(9) Hartman, R. L.; Naber, J. R.; Zaborenko, N.; Buchwald, S. L.; Jensen, K. F. Overcoming the challenges of solid bridging and constriction during Pd-Catalyzed $\mathrm{C}-\mathrm{N}$ bond formation in microreactors. Org. Process Res. Dev. 2010, 14, 1347-1357.

(10) a) Murphy, E. R.; Martinelli, J. R.; Zaborenko, N.; Buchwald, S. L.; Jensen, K. F. Accelerating Reactions with Microreactors at Elevated Temperatures and Pressures: Profiling Aminocarbonylation Reactions. Angew. Chem. 2007, 119, 1764-1767; Angew. Chem. Int. Ed. 2007, 46, 1734-1737; b) Tundel, R. E.; Anderson, K. W.; Buchwald, S. L. Expedited Palladium-Catalyzed Amination of Aryl Nonaflates through the Use of Microwave-Irradiation and Soluble Organic Amine Bases. J. Org. Chem. 2006, 71, 430-433.

(11) Naber, J. R.; Buchwald, S. L. Packed-Bed Reactors for Continuous-Flow C-N Cross-Coupling. Angew. Chem. 2010, 122, 9659-9664; Angew. Chem., Int. Ed. 2010, 49, 9469-9474.

(12) Kirschning, A.; Solodenko, W.; Mennecke, K. Combining Enabling Techniques in Organic Synthesis: Continuous Flow Processes with Heterogenized Catalysts. Chem. Eur. J. 2006, 12, 5972-5990.

(13) a) McKeown, N. B.; Budd, P. M. Polymers of intrinsic microporosity (PIMs): organic materials for membrane separations, heterogeneous catalysis and hydrogen storage. Chem. Soc. Rev. 2006, 35, 675-683; b) Thomas, A. Functional Materials: From Hard to Soft Porous Frameworks. Angew. Chem. 2010, 122, 8506-8523; Angew. Chem. Int. Edit. 2010, 49, 8328-8344.

(14) a) Lu, J.; Toy, P. H. Organic Polymer Supports for Synthesis and for Reagent and Catalyst Immobilization. Chem. Rev. 2009, 109, 815-838; b) Buchmeiser, M. R. PolymerSupported Well-Defined Metathesis Catalysts. Chem. Rev. 2008, 109, 303-321.

(15) Li, R. H.; An, X. M.; Yang, Y.; Li, D. C.; Hu, Z. L.; Zhan, Z. P. Highly Regio- and Stereoselective Heterogeneous Hydrosilylation of
Terminal Alkynes over Cobalt-Metalated Porous Organic Polymer. Org. Lett. 2018, 20, 5023-5026.

(16) Chemical Process Technology (Eds.: Moulijn, J. A.; Makkee, Ir. M.; Dieper, A. E van), Wiley, New York, 2001.

(17) a) Svec, F. Porous polymer monoliths: amazingly wide variety of techniques enabling their preparation. $J$. Chromatogr. A 2010, 1217, 902-924; b) Siouff, A. M. About the $C$ term in the van Deemter's equation of plate height in monoliths. J. Chromatogr. A 2006, 1126, 86-94.

(18) Sans, V.; Karbass, N.; Burguete, M. I.; García-Verdugo, E.; Luis, $\mathrm{S}$. V. Residence time distribution, a simple tool to understand the behaviour of polymeric mini-flow reactors. RSC Adv. 2012, 2, 8721-8728.

(19) Tertiary phosphine has been immobilized on polystyrenebased monolith, see; Barlow, K. J.; Bernabeu, V.; Hao, X.; Hughes, T. C.; Hutt, O. E.; Polyzos, A.; Turner, K. A.; Moad, G. Triphenylphosphine-grafted, RAFT-synthesised, porous monoliths as catalysts for Michael addition in flow synthesis. React. Funct. Polym. 2015, 96, 89-96. However, the application of the monolith was limited to a continuous-flow organocatalysis.

(20) Macroporous polymer monoliths containing NHC, pyridine, bipyridine, and pybox have been developed and applied to transition-metal catalyses in continuous-flow modes, see: a) Karbass, N.; Sans, V.; Garcia-Verdugo, E.; Burguete, M. I.; Luis, S. V. Pd(0) supported onto monolithic polymers containing IL-like moieties. Continuous flow catalysis for the Heck reaction in near-critical EtOH. Chem. Commun. 2006, 29, 3095-3097; b) Rojo, M. V.; Guetzoyan, L.; Baxendale, I. R. A monolith immobilised iridium $\mathrm{Cp}^{*}$ catalyst for hydrogen transfer reactions under flow conditions. Org. Biomol. Chem. 2015, 13, 1768-1777; c) Bolton, K. F.; Canty, A. J.; Deverell, J. A.; Guijt, R. M.; Hilder, E. F.; Rodemann, T.; Smith, J. A. Macroporous monolith supports for continuous flow capillary microreactors. Tetrahedron Lett. 2006, 47, 93219324; d) Burguete, M. I.; Cornejo, A.; García-Verdugo, E.; Gil, M. J.; Luis, S. V.; Mayoral, J. A.; Martínez-Merino, V.; Sokolova, M. Pybox Monolithic Miniflow Reactors for Continuous Asymmetric Cyclopropanation Reaction under Conventional and Supercritical Conditions. J. Org. Chem. 2007, 72, 43444350.

(21) Cameron, N. R.; Sherrington, D. C. Preparation and glass transition temperatures of elastomeric PolyHIPE materials. J. Mater. Chem. 1997, 7, 2209-2212.

(22) See supporting information (SI) for the synthesis of polymerizable TPP and monoliths containing TPP (Scheme S1-S4).

(23) Kovačič, S.; Krajnc, P. Macroporous monolithic poly(4vinylbenzyl chloride) columns for organic synthesis facilitation by in situ polymerization of high internal phase emulsions. J. Polym. Sci. Pol. Chem. 2009, 47, 6726-6734.

(24) Further elongation of polymerization time ( $>6 \mathrm{~h}$ ) had no meaningful change of yield and macroporous structure, see SI (Table S1 and Figure S1).

(25) See SI for the ${ }^{31 P}$ CP/MAS NMR analyses of monoliths containing TPP (Figures S6 and S7).

(26) See SI for the preparation and permeabilities of monolith columns in continuous-flow reactor (Figures S8 and S9, Table S3).

(27) Tebboth, M.; Kogelbauer, A.; Bismarck, A. Liquid-Liquid Extraction within Emulsion Templated Macroporous Polymers. Ind. Eng. Chem. Res. 2015, 54, 7284-7291.

(28) See SI for the continuous-flow setup for RTD experiments (Figure $\mathrm{S} 10$ ), $E(\theta)$ curves at different $\tau$ (Figure S11), and analytical parameters (Table S4) for M-PS-TPP column.

(29) Urban, J.; Eeltink, S.; Jandera, P.; Schoenmakers, P. J. Characterization of polymer-based monolithic capillary columns by inverse size-exclusion chromatography and mercury-intrusion porosimetry. J. Chromatogr. A 2008, 1182, 161-168. 
(30) For a active and durable Pd catalyst effectively confined within a cross-linked polymer under continuous-flow conditions, see: a) Matsumoto, H.; Seto, H.; Akiyoshi, T.; Shibuya, M.; Hoshino, Y.; Miura, Y. Macroporous Gel with a Permeable Reaction Platform for Catalytic Flow Synthesis. ACS Omega 2017, 2, 8796-8802; b) Matsumoto, H.; Seto, H.; Akiyoshi, T.; Shibuya, M.; Hoshino, Y.; Miura, Y. Macroporous monolith with polymer gel matrix as continuous-flow catalytic reactor. Chem. Lett. 2017, 46, 1065-1067.

(31) See SI for the procedures for cross-coupling reaction in continuous-flow system using M-PS-TPP-Pd column.

(32) a) Koreniuk, A.; Maresz, K.; Odrozek, K.; Jarzębski, A. B.; Mrowiec-Białoń, J. Highly effective continuous-flow monolithic silica microreactors for acid catalyzed processes. Appl. Catal. A-Gen. 2015, 489, 203-208; b) Sachse, A.; Hulea, V.; Finiels, A.; Coq, B.; Fajula, F.; Galarneau, A. Aluminagrafted macro-/mesoporous silica monoliths as continuous flow microreactors for the Diels-Alder reaction. J. Catal. 2012, 287, 62-67.
(33) See SI for the TEM images of M-PS-TPP-Pd before and after run (Figures S12 and S13).

(34) Ichitsuka, T.; Suzuki, N.; Sairenji, M.; Koumura, N.; Onozawa, S. Y.; Sato, K.; Kobayashi, S. Readily Available Immobilized Pd Catalysts for Suzuki - Miyaura Coupling under Continuous flow Conditions. ChemCatChem 2019, 11, 2427-2431.

(35) M-PS-TPP was powdered using pestle and mortar for batch catalysis. See SI for the details (Figure S14).

(36) a) Phan N. T.; Khan, J.; Styring, P. Polymer-supported palladium catalysed Suzuki-Miyaura reactions in batch and a mini-continuous flow reactor system. Tetrahedron 2005, 61, 12065-12073; b) Pascanu, V.; Hansen, P. R.; Bermejo Gómez, A.; Ayats, C.; Platero-Prats, A. E.; Johansson, M. J.; Pericàs, M. Á.; Martín-Matute, B. Highly Functionalized Biaryls via Suzuki-Miyaura Cross - Coupling Catalyzed by Pd@MOF under Batch and Continuous Flow Regimes. ChemSusChem 2015, 8, 123-130. 
For Table of Contents Only

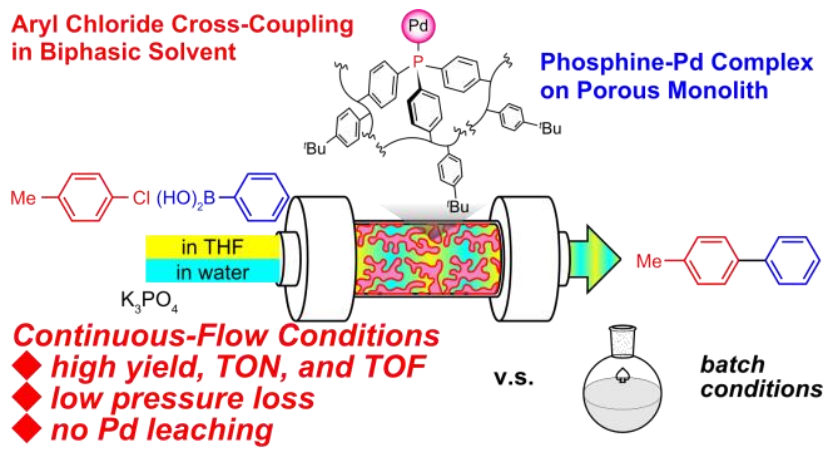

